\title{
Hydrogenation of Alkenes Using Copper Nanoparticles Supported on Diamond
}

Key words

copper nanoparticles

diamond nanoparticles

hydrogenation

alkenes
Selected examples:<smiles>CCc1ccccc1</smiles>

$100 \%$ conversion $>99 \%$ selectivity<smiles>CC(C)c1ccccc1</smiles>

$99 \%$ conversion $98 \%$ selectivity

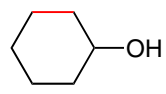

$95 \%$ conversion $99 \%$ selectivity

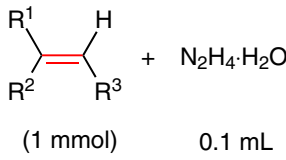

$$
\begin{aligned}
& \underset{\mathrm{Cu} / \mathrm{DH}(0.16 \mathrm{~mol} \% \mathrm{Cu})}{\stackrel{\text { aq NH}}{ }(0.025 \mathrm{~mL})} \\
& \text { EtOH }(4 \mathrm{~mL}), 60^{\circ} \mathrm{C}
\end{aligned}
$$$$
\text { 3-33 h }
$$

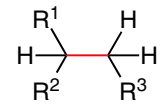

19 examples

60-100\% conversion 96 to $>99 \%$ selectivity<smiles>CCOC(=O)CCc1ccc([N+](=O)[O-])cc1</smiles>

$$
89 \% \text { conversion }
$$

conversion

$99 \%$ selectivity<smiles>CCc1ccncc1</smiles>

$95 \%$ conversion $99 \%$ selectivity<smiles>CCCSc1ccccc1</smiles>

99\% conversion $96 \%$ selectivity

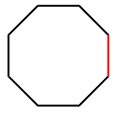

$99 \%$ conversion $99 \%$ selectivity<smiles>CCCOc1ccccc1</smiles>

99\% conversion $99 \%$ selectivity
Significance: Copper nanoparticles supported on diamond nanoparticles $(\mathrm{Cu} / \mathrm{DH})$ catalyzed the hydrogenation of alkenes with $\mathrm{N}_{2} \mathrm{H}_{4} \cdot \mathrm{H}_{2} \mathrm{O}$ to give the corresponding alkanes in 60-100\% conversion with selectivities of the desired products from 96 to $>99 \%$ (19 examples, eq. 1). The catalyst was recovered by centrifugation and reused three times without significant loss of the catalytic activity in the hydrogenation of styrene $\left(3^{\text {th }}\right.$ reuse: $94 \%$ conversion, $>99 \%$ selectivity).
Comment: The authors previously reported the preparation of $\mathrm{Cu} / \mathrm{DH}$ and their application to the aerobic oxidation of thiols (ChemCatChem $\mathbf{2 0 1 3}$, $5,241)$. The catalytic activity of $\mathrm{Cu} / \mathrm{DH}$ was superior to that of copper nanoparticles supported on activated carbon, graphite, and multi-walled carbon nanotubes and gold and palladium nanoparticles supported on DH. Phenyl acetylene underwent the hydrogenation under similar conditions to give styrene and ethylbenzene (39\% conversion; styrene/ethylbenzene $=61: 39$ ). 